\title{
Probabilistic Markov Model Estimating Cost Effectiveness of Methylphenidate Osmotic-Release Oral System Versus Immediate-Release Methylphenidate in Children and Adolescents: Which Information is Needed?
}

\author{
Saskia Schawo • Annemarie van der Kolk · Clazien Bouwmans • \\ Lieven Annemans • Maarten Postma • Jan Buitelaar • \\ Michel van Agthoven • Leona Hakkaart-van Roijen \\ Published online: 26 February 2015 \\ (C) The Author(s) 2015. This article is published with open access at Springerlink.com
}

\begin{abstract}
Background Incidence of attention deficit hyperactivity disorder (ADHD) in children and adolescents has been increasing. The disorder results in high societal costs. Policymakers increasingly use health economic evaluations to inform decisions on competing treatments of ADHD. Yet, health economic evaluations of first-choice medication of ADHD in children and adolescents are scarce and generally do not include broader societal effects.

Objectives This study presents a probabilistic model and analysis of methylphenidate osmotic-release oral system (OROS) versus methylphenidate immediate-release (IR). We investigate and include relevant societal aspects in the analysis so as to provide cost-effectiveness estimates based on a broad societal perspective.

Methods We enhanced an existing Markov model and determined the cost effectiveness of OROS versus IR for
\end{abstract}

S. Schawo · C. Bouwmans · L. Hakkaart-van Roijen Institute for Medical Technology Assessment and Institute of Health Policy and Management, Erasmus University Rotterdam, Rotterdam, The Netherlands

\section{S. Schawo $(\bowtie)$}

Institute for Medical Technology Assessment, Erasmus University Rotterdam, Room J5-055, P.O. Box 1738, 3000 DR Rotterdam, The Netherlands

e-mail: hakkaart@bmg.eur.nl

A. van der Kolk

Janssen-Cilag B.V., Tilburg, The Netherlands

\section{Annemans}

Interuniversity Centre for Health Economics Research,

Ghent University, Ghent, Belgium

\section{Annemans}

Brussels University, Brussels, Belgium children and adolescents responding suboptimally to treatment with IR. Enhancements included screening of a broad literature base, updated utility values, inclusion of costs and effects on caregivers and a change of the model type from deterministic to probabilistic.

Results The base case scenario resulted in lower incremental costs $(€-5815)$ of OROS compared with IR and higher incremental quality-adjusted life-year (QALY) gains (0.22). Scenario analyses were performed to determine sensitivity to changes in transition rates, utility of caregivers, medical costs of caregivers and daily medication dose.

Conclusions The results indicate that, for children responding suboptimally to treatment with IR, the beneficial effect of OROS on compliance may be worth the additional costs of medication. The presented model adds to the health economic information available for policymakers

M. Postma

Unit of Pharmaco Epidemiology and Pharmaco Economics,

Department of Pharmacy, University of Groningen,

Groningen, The Netherlands

J. Buitelaar

Department of Cognitive Neuroscience, Nijmegen Centre for

Evidence Based Medicine, Radboud University Medical Centre,

Nijmegen, The Netherlands

J. Buitelaar

Karakter Child and Adolescent Psychiatry University Centre,

Nijmegen, The Netherlands

M. van Agthoven

Gilead Sciences Netherlands B.V., Amsterdam, The Netherlands 
and to considerations on a broader perspective in cost-effectiveness analyses.

\section{Key Points for Decision Makers}

There is a lack of economic studies on attention deficit hyperactivity disorder (ADHD) in children and adolescents with a broader societal perspective.

We present a probabilistic model of methylphenidate osmotic-release oral system (OROS) versus methylphenidate immediate-release (IR), considering and integrating relevant broader societal aspects.

The base case scenario resulted in lower incremental costs (€-5815) of OROS compared with IR and higher incremental quality-adjusted life-year gains (0.22).

Scenario analyses showed particular sensitivity to changes in transition rates.

The study contributes to the movement towards broader societal considerations in cost-effectiveness analyses and to the provision of comprehensive health economic evidence for policymakers and clinicians in mental health care.

Like other authors in the field, we recognize a lack of data; future research should be especially directed at the collection of empirical data on transition estimates, utility values of caregivers and broader societal aspects of the disorder, such as criminal justice costs.

\section{Introduction}

An increasing incidence of attention deficit hyperactivity disorder (ADHD) in children [1] and high use of pharmacological treatments [2] have become relevant issues for policymakers and mental health professionals. It is yet unclear whether the increase in incidence is due to changes in true numbers of patients or whether numbers appear higher as a consequence of differences in diagnosis or recall of parents [3]. The high number of young ADHD patients results in significant societal costs [4]. Evidence from literature suggests that 50-70\% of those suffering from ADHD in childhood also experience ADHD as an adult [5, 6]. Hence, costs are not limited to the short term; ADHD may also result in lower household income, mental and physical dysfunction, comorbidities and increased health consumption later on in life [6, 7] as well as increased health care consumption and productivity losses of household members [8].

First-choice medication for treatment of ADHD in the Netherlands is the stimulant methylphenidate (MPH) [9]. MPH is available as a short-acting as well as a more costly long-acting formulation. Different formulations are available from a wide selection of brands and in different strengths. Short-acting MPH requires accurate medication intake 2-5 times a day [9]. Consequently, medication intake may require high effort and impose practical difficulties, for example, on children attending school. The long-acting formula has been developed to overcome those practical problems of medication intake and compliance by using a once-a-day treatment scheme [10]. Existing clinical studies suggest no significant difference between the efficacy of short-acting and long-acting MPH under the assumption of full therapy compliance [10-12]. However, it has been shown that lower frequency of medication intake is correlated with better treatment compliance [13]. Longacting MPH has been shown to be associated with better treatment continuity [14, 15]. Kemner and Lage [14] found patients treated with long-acting MPH to be subject to less breaks in medication use, fewer medication switches and a longer period on intended therapy. Marcus et al. [15] stated that the treatment duration of patients with long-acting MPH was on average longer than for patients treated with short-acting MPH. Long-acting formulations of MPH have also been proven to result in superior compliance in patients when compared with the short-acting formulation [16-18], hence, possibly leading to better effectiveness than the short-acting formulation.

However, it is not evident whether the effect of longacting formulations of MPH can justify the higher costs. Given the scarce financial resources in health care, costeffectiveness analyses have become essential to inform policymakers' choices between competing treatments and to provide well-founded recommendations to clinicians within clinical guidelines. However, evidence in the form of recent state-of-the-art health economic evaluations of ADHD treatment in children is limited. Furthermore, there is increasing debate on whether it is sufficient to purely evaluate interventions on the basis of costs and effects in the domain of health care and limit these to the patient alone [19]. Authors of recent publications emphasized the lack of economic studies on ADHD in children and adolescents with a broader societal perspective [20-22]. Bernfort et al. [21] found that most often societal costs were not included in economic evaluations of ADHD. Wu et al. [22] performed a systematic literature review on health care costs of family members of children with ADHD and found those costs to be higher than those of families without a child with ADHD. Beecham [20] stated 
that "economic evaluation of interventions for child and adolescent psychiatric disorders has lagged some way behind its adult counterpart." She expressed the need for a broader perspective as to reflect the various effects of psychiatric disorders in children and adolescents [20]. Evidence from the literature on meningitis [23] suggests that 'spillover' health effects on family may constitute as much as $48 \%$ of the health effects on the patient. As ADHD can be considered especially stressful on the direct environment of the patient, such as parents, siblings, friends or schoolmates, this percentage may even be larger for patients with ADHD. Hence, the inclusion of broader societal effects and costs is considered necessary [22].

Bernfort et al. [21] recommended the use of a health economic Markov model to determine the long-term costs and effects of ADHD. However, the authors stated that sufficiently detailed data (especially on long-term consequences of ADHD) was scarce or unavailable [21]. King et al. [24] expressed their concerns on the limited availability of effectiveness estimates and utility values, possibly due to scarcity of clinical data. Among the health economic evaluations that have been performed to evaluate various pharmacological treatments of ADHD are analyses based on decision analytic trees [25] and cost-of-illness calculations [26]. A small number of evaluations have been performed based on more advanced health economic (Markov) models [24, 27, 28]. However, there is a lack of more recent studies in the field. An economic evaluation on long-acting MPH osmotic-release oral system (OROS) versus short-acting MPH immediate-release (IR) suggested better cost effectiveness of OROS (hereafter referred to as the Faber model) [29]. However, that evaluation was limited compared with the current standard of health economic modeling as a deterministic model was employed and only effects limited to the patient were included. Hence, clear health economic recommendations on the cost effectiveness of OROS compared with IR based on a broad societal perspective are still lacking.

Knowledge of the cost effectiveness of treatment options for children with ADHD is essential in order to inform policymakers and enable the formulation of specific recommendations in clinical guidelines. In the case of $\mathrm{MPH}$, it would be desirable to provide clear recommendations on which formulation is to be preferred under which circumstances, founded on sound and comprehensive health economic evidence. This study aims to contribute to this goal. We perform a cost-effectiveness evaluation of OROS versus IR in line with current health economic methodology, based on the Faber model [29], but with a probabilistic model update, enhanced model structure, updated input parameters (including utility values) and a broader societal perspective (i.e., we considered criminal justice costs, educational costs, employment disadvantages, out-of-pocket-expenses, medical and productivity costs and utility values of the caregiver). Additionally, we provide specific recommendations for future data collection, which would be valuable to further increase the validity of the model outcomes.

\section{Methods}

We evaluated the cost effectiveness of OROS compared with IR for patients with suboptimal response to IR. The structure of the probabilistic Markov model and its parameters was defined according to the Dutch guidelines for pharmacoeconomic evaluation [30].

According to health economic standards, a societal perspective was taken to reflect costs and effects on patients, their parents and society as a whole [31]. We searched literature on a broad range of cost categories for relevance and feasibility of inclusion in the model (i.e., criminal justice costs, lower income, out-of pocket expenses of the patient as well as health care costs and productivity costs of caregivers). Direct medical and nonmedical costs as well as spillover effects on caregivers were included in the model.

\subsection{Consultation of Experts}

As part of this study, a panel of experienced psychiatrists from various regions in the Netherlands was consulted (Table 1). These experts were asked to provide feedback on the model structure, input and model assumptions as well as estimates of transition probabilities. Transition probabilities were retrieved in accordance with the Delphi panel requirements [30], and other issues were discussed individually. After discussion with the expert panel on, among others, the definition of health states and the cycle length of the probabilistic model, the cycle length was chosen to remain unchanged and the model states were slightly adapted as opposed to the Faber model [29] to better match patient characteristics, illness and treatment approach.

\subsection{General Model Characteristics}

The probabilistic model was based on the existing deterministic model by Faber et al. [29]. Model type, model state definitions, time horizon, model parameters and model input (including utility values) were updated to enhance the existing model and to comply with current health economic methodology (Table 2).

As the Faber model was limited to a deterministic decision-analytic model with sensitivity analyses, we chose a more advanced probabilistic approach. The 
Table 1 Consulted experts

\begin{tabular}{|c|c|c|c|c|c|c|c|c|}
\hline Expert & Gender & $\begin{array}{l}\text { Age } \\
\text { (years) }\end{array}$ & Specialism & Subspecialism & $\begin{array}{l}\text { Years } \\
\text { experience } \\
\text { in mental } \\
\text { health }\end{array}$ & $\begin{array}{l}\text { Average number of } \\
\text { patients } \\
\text { with ADHD from } 6 \text { to } \\
18 \text { years of age seen } \\
\text { per month }\end{array}$ & $\begin{array}{l}\text { Years } \\
\text { experience } \\
\text { with } \\
\text { ADHD } \\
\text { medication }\end{array}$ & $\begin{array}{l}\text { Average } \\
\text { number of } \\
\text { patients seen } \\
\text { per month }\end{array}$ \\
\hline 1 & M & 55 & $\begin{array}{l}\text { Child and youth } \\
\text { psychiatrist }\end{array}$ & None & 24 & 90 & 16 & 105 \\
\hline 2 & M & 52 & $\begin{array}{l}\text { Child and youth } \\
\text { psychiatrist }\end{array}$ & $\begin{array}{l}\text { Hospital, child psychiatry } \\
\text { and ADHD }\end{array}$ & 22 & $>30$ & 16 & $>100$ \\
\hline 3 & $\mathrm{~F}$ & 43 & $\begin{array}{l}\text { Child and youth } \\
\text { psychiatrist }\end{array}$ & ADHD/ODD/ticks & 13 & 45 & 10 & 50 \\
\hline 4 & M & 55 & Child psychiatrist & Neuropsychiatry & 29 & 50 & 22 & 80 \\
\hline
\end{tabular}

$A D H D$ attention deficit hyperactivity disorder, $O D D$ oppositional defiant disorder

Table 2 Current model vs. Faber model

\begin{tabular}{|c|c|}
\hline Current model & Faber model [29] \\
\hline \multicolumn{2}{|c|}{$\begin{array}{l}\text { General model type: Markov model } \\
\text { Perspective: societal } \\
\text { Cycle length: } 1 \text { day } \\
\text { Resource use estimates: expert panel (Faber et al. [29]) } \\
\text { Outcomes: expressed as cost/QALY }\end{array}$} \\
\hline Utility estimates & Utility estimates \\
\hline Patient and caregiver & Patient \\
\hline Reference of utility estimates & Reference of utility estimates \\
\hline van der Kolk et al. [57] & Secnik et al. [32] \\
\hline Specific model type & Specific model type \\
\hline Probabilistic & Deterministic \\
\hline Model states OROS/IR & Model states OROS \\
\hline Optimal, suboptimal, treatment stopped, remission & $\begin{array}{l}\text { Optimal, non compliance, treatment stopped, functional remission } \\
\text { Model states IR } \\
\text { optimal, suboptimal, treatment stopped, functional remission }\end{array}$ \\
\hline Patient age when entering model & Patient age when entering model \\
\hline 6 years & 8 years \\
\hline Time horizon & Time horizon \\
\hline 12 years & 10 years \\
\hline Transition rate estimates & Transition rate estimates \\
\hline Delphi panel of experts & various sources (literature and expert opinion) \\
\hline Cost categories & Cost categories \\
\hline $\begin{array}{l}\text { Patient: medication costs, consultation costs, intervention costs, } \\
\text { special education costs }\end{array}$ & $\begin{array}{l}\text { Patient: medication costs, consultation costs, intervention costs, } \\
\text { special education costs }\end{array}$ \\
\hline \multicolumn{2}{|l|}{ Caregiver: medical costs, production losses } \\
\hline Cost parameter values & Cost parameter values \\
\hline $2014 €$ & $2005 €$ \\
\hline
\end{tabular}

IR immediate-release, OROS osmotic-release oral system, $Q A L Y$ quality-adjusted life-year

consideration of uncertainty increasingly gains importance, as shown in several guidelines, of which one explicitly suggests the use of probabilistic sensitivity analysis [33]. Therefore, input parameters were set to vary according to prior distributions as to introduce parameter uncertainty in the model.
Furthermore, we refined and improved model state definitions. Where Faber et al. [29] considered five model states (optimal, suboptimal, treatment stopped, functional remission and non-compliance), with different states applicable for different treatment conditions, the current model defined four model states (optimal, suboptimal, 
treatment stopped and remission) consistent across treatment conditions.

The time horizon of the model was slightly adjusted in the current model. Patients entered the Faber model [29] at 8 years of age and remained in the model for 10 years. In the current model, we redefined the starting age of patients entering the model to 6 years and extended the time horizon to 12 years in order to be in line with the treatment guidelines for ADHD [9]. The relevant patient population was defined as patients within this age group who initially had responded suboptimally to IR because of incorrect intake of medication (i.e., missing doses of medication due to administrative burden). To simulate a randomized population, it was assumed that half of the initial patient population continued to receive IR and the other half switched to treatment with OROS when entering the model.

Within the current model, the assumed cycle length was 1 day and was consistent with the set-up of the Faber model. The panel of experts (Table 1) indicated that a cycle length in line with the prescription regimen of a day would be most appropriate and consistent as non-compliance to medication would, on average, result in a change in behavior on the same day for almost all children, with only few exceptions. This cycle length implies that an improvement or worsening of compliance can occur on a daily basis and symptoms and costs change accordingly after 1 day. In reality, costs may adjust less quickly than effects, resulting in less volatility in costs than assumed in the model.

The prescribed dosage of medication was assumed optimal for all patients based on age and metabolism. In line with the Multimodal Treatment of attention deficit hyperactivity disorder (MTA) study [34] and expert comments, a mean of 3 doses IR per day and 1 dose OROS per day were assumed.

Costs and effects were discounted at 4 and $1.5 \%$, respectively, according to the Dutch guidelines for pharmacoeconomic research [30].

\subsection{Model States}

The effect of medication was evaluated in terms of ADHD symptoms and behavioral change. The model distinguished four different health states (Table 3). The definition of the health states was based on the Faber model [29] and enhanced with feedback from the expert panel. Where Faber et al. [29] made a distinction between a suboptimal state for treatment with IR and the state of non-compliance for treatment with OROS, the updated model made use of a consistent health state definition over treatments. The noncompliance state was replaced by the suboptimal state, now defined as a state in which medication was skipped and exposure to medication was insufficient for either IR or OROS.

In the optimal state, patients were assumed to adhere to the prescribed medication and consequently not experience

Table 3 Definition of model states

\begin{tabular}{|c|c|c|c|}
\hline \multirow[t]{2}{*}{ Health state } & \multirow[t]{2}{*}{ Definition } & \multicolumn{2}{|c|}{ Medication intake per day } \\
\hline & & OROS & IR \\
\hline Optimal $(\mathrm{A})^{\mathrm{a}}$ & $\begin{array}{l}\text { Optimal }^{\mathrm{a}} \text { daily exposure to medication; remission } \\
\text { b of ADHD symptoms; the child } \\
\text { functions well with this treatment; no significant problems at home, at school, with } \\
\text { peers or during leisure time; the child receives additional care, such as visits to a } \\
\text { specialist, behavioral therapy, extra attention at school, etc }\end{array}$ & $1 \times$ & $3 \times$ \\
\hline Suboptimal $(B)^{\mathrm{c}}$ & $\begin{array}{l}\text { Insufficient daily exposure to medication; ADHD symptoms present, but reduced, } \\
\text { different from normal functioning; the child functions considerably well with this } \\
\text { treatment; during short periods, the child experiences problems at home, at school, } \\
\text { with peers or during leisure time; the child receives additional care, such as visits to a } \\
\text { specialist, behavioral therapy, extra attention at school, etc }\end{array}$ & None & $0-2 \times$ \\
\hline Treatment stopped (C) & $\begin{array}{l}\text { Treatment stopped in spite of remaining symptoms of ADHD; noticeable problems at } \\
\text { home, at school, with peers and/or during leisure time; the child experiences more } \\
\text { continuous hinder of those problems; the child receives additional care, such as visits } \\
\text { to a specialist, behavioral therapy, extra attention at school, etc }\end{array}$ & None & None \\
\hline Remission (D) & $\begin{array}{l}\text { No medication used; behavioral problems are no more different from normal; no more } \\
\text { additional care needed related to ADHD, such as visits to a specialist, behavioral } \\
\text { therapy, extra attention at school, etc }\end{array}$ & None & None \\
\hline
\end{tabular}

$A D H D$ attention deficit hyperactivity disorder, IR immediate-release, OROS osmotic-release oral system

a Optimal intake is defined as follows: good compliance with intake of $1 \times /$ day for OROS and $3 \times /$ day for IR

${ }^{\mathrm{b}}$ Remission: not different from normal, symptoms of ADHD are at the most sometimes present, but not often or always

c Suboptimal intake: insufficient compliance. Medication is not taken as prescribed, which means no intake for OROS and an average intake of $1 \times /$ day for IR 


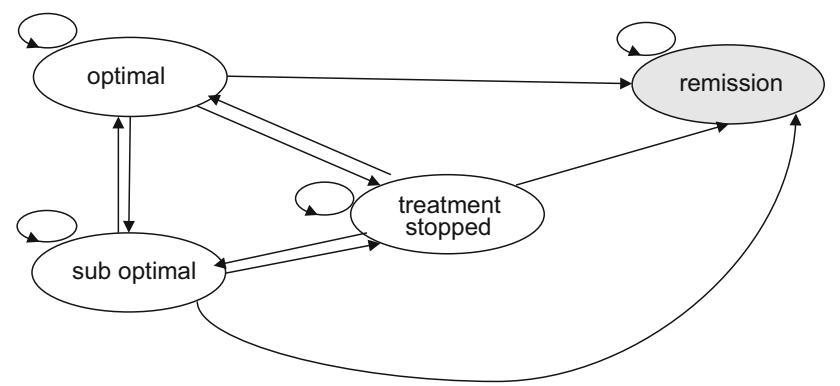

Fig. 1 Graphical representation of the model

any symptoms of ADHD. Symptoms not directly related to ADHD but to comorbidity may still be present in this state. In a suboptimal state, in contrast, patients were assumed not to adhere properly to their prescribed medication, resulting in symptoms of ADHD and behavior different from normal behavior for their age group. As a single dose of OROS was required per day, skipping medication meant no medication at all in that state. For patients treated with IR, non-adherence at a mean of 3 prescribed doses per day [9] was assumed as missing 1, 2 or 3 doses per day, yielding a mean of 2 missed doses per day in the suboptimal state.

Patients who stopped treatment entirely in spite of remaining symptoms of ADHD entered the state 'treatment stopped.' Patients with functional remission not needing medication for treatment of ADHD entered the state 'remission.' In line with the study performed by Faber et al. [29], we assumed that once in remission, patients remained in that state, which acted as an absorbing state (Fig. 1). The consulted psychiatrists indicated that reaching the state of remission would be exceptional. According to the experts, the assumption of remission as an absorbing state could reasonably be made. However, the experts noted that there may be exceptions where patients experience a relapse after having reached the state of remission.

Patients in an optimal, suboptimal or treatment stopped state either remained in that state or transferred to one of the other states.

\subsection{Transition Rates}

Variation in effect was modeled based on compliance and resulting symptom and behavior change (Table 3). Data on transition rates between model states had to comply with our specific target population (i.e., children or adolescents with ADHD who initially had responded suboptimally to IR because of incorrect intake of medication). Furthermore, to guarantee the validity of model results, we preferred transition rates departing from one state to different states to all originate from the same source (and refer to the same definition of an optimal and suboptimal state). We considered transition rates from the Faber model [29] suboptimal as some of the transition rates were counterintuitive and the rates were based on multiple sources (i.e., literature and expert opinion). Hence, we performed a systematic literature review in the PubMed, PsycInfo and ERIC databases to identify data to determine the transitions. First, we searched for reviews for the period from January 1, 2008 (the year of publication of the Faber model [29]) onwards. This search was performed on November 9 , 2014. Then, we performed an additional search in the same databases, directed at recent clinical trials from the publication date of the most recent identified review onwards. This second search was performed on December 8, 2014. Search terms for both searches were as follows: ADHD OR "attention deficit hyperactivity disorder" [title]; AND methylphenidate OR MPH OR MPH-IR OR MPH-ER OR pharmaco* [title]; AND effect* OR efficacy OR cost-effectiveness OR cost-utility [title].

The searches resulted in a total of 121 hits after duplicates were removed. The records were screened by two researchers independently, in a first round on title and in a second round on abstract. Where there was conflict, a decision was reached through consensus. The screening and selection process is summarized in a PRISMA flow diagram in Fig. 2.

The selections based on title and abstract resulted in 16 studies to be included, among which were seven reviews and nine clinical trials. We were specifically interested in data from which transition rates for OROS and/or IR could be derived. Consultation of the reviews yielded several conclusions. Five reviews presented only mean scores on specific outcome measures [35, 36] or effect sizes [37-39]. Confidence intervals of effect sizes may be used to calculate transition rates based on a minimal meaningful improvement (i.e., defining a certain point on the distribution at which a patient moves from an optimal towards a suboptimal model state). However, as different underlying studies used different outcomes as the basis for the stated effect sizes, minimal meaningful improvements (and, hence, definition of the suboptimal model state) would differ per outcome measure and per study. Hence, we did not consider this approach a feasible option within the scope of this study. Another review presented information on pharmacokinetics [40]. One other study concerned a review of cost-effectiveness outcomes, not presenting specific data on state transitions [41]. None of the reviews specifically addressed the targeted patient population (i.e., children or adolescents who had initially responded suboptimally to IR because of incorrect intake of medication). Hence, we considered the option to base transition estimates on a single study and examined the recent articles for further informative data. From consultation of these articles, we noted that seven of the nine articles did not contain suitable information. Two articles concerned letters to the 
Fig. 2 PRISMA flow diagram of systematic literature review. ${ }^{a}$ Reasons: $O$ document type: review (review search)/clinical trial (clinical trial search); 1 treatment: pharmacological treatment (of which $\geq 1 \mathrm{MPH}$ in pill form); 2 age group: 6-18 years (child/adolescent); 3 population: ADHD patients (no combined diagnosis or extreme symptom type of ADHD); 4 type of outcome measured in terms of functioning: response, effect, effectiveness, efficacy, cost-effectiveness or costutility. $A D H D$ attention deficit hyperactivity disorder, $M P H$ methylphenidate. Adapted from Moher D, Liberati A, Tetzlaff J, Altman DG, The PRISMA Group (2009). Preferred Reporting Items for Systematic Reviews and Meta-Analyses: The PRISMA Statement. PLoS Med 6(6): e1000097. doi:10. 1371/journal.pmed1000097
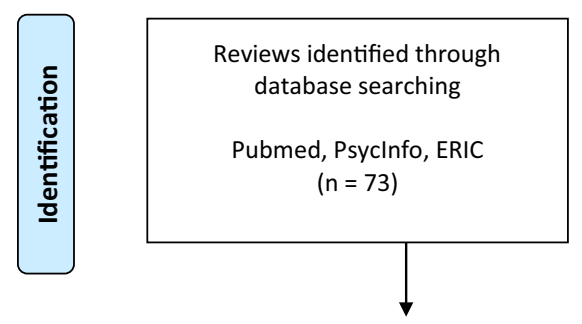

(Recent) articles identified through database searching

Pubmed, PsycInfo, ERIC $(n=68)$

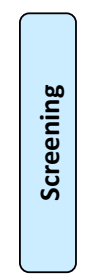

Records after duplicates removed $(n=121)$

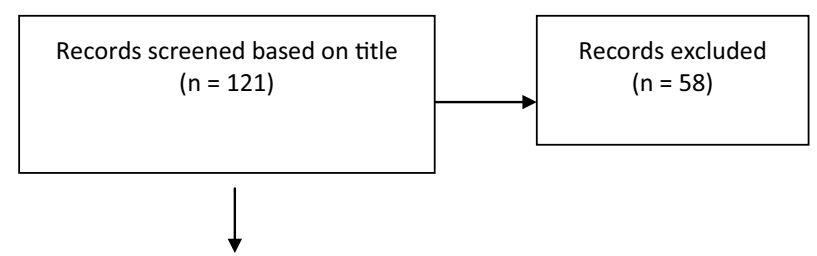

Records screened based on abstract $(n=63)$

Records excluded with reasons $(n=47)$ [reviews: $19(0), 3(1), 1(2), 1$ (3), 4 (4); articles: $3(0), 1$ (1), $0(2), 1(3), 14(4)]^{a}$

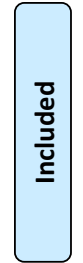

editor [42, 43], one article was written in Iranian language [44], one article concerned an explanatory study on effect sizes [45], one article presented mean scores [46] and one article referred to differences in scores [47]. Another article presented percentages of patients who improved (a potentially suitable measure for the calculation of transition probabilities). However, the study considered patients treated with specific extended-release MPH with $50 \%$ short-acting and $50 \%$ long-acting components [48]. Two remaining articles presented data potentially useful for calculation of transition rates [49, 50]. Garg et al. [49] found a treatment response of $90.7 \%$ in patients receiving IR $(n=33)$ in Northern India. Soutullo et al. [50] stated that $51 \%(95 \%$ CI 31.1-60.6) of European patients $(n=111)$ responded to treatment with OROS. The trial was performed in 48 centers across ten European countries. However, both articles did not consider the specific patient population of this study and only one broad rate of response for the entire treatment period was provided, whereas our model included more specific transitions between the optimal and suboptimal states (back and forth) and accounted separately for patients staying in a specific state. Furthermore, Garg et al. [49] and Soutullo et al. [50] used different outcome measures to define response and the studies were performed in two different treatment populations. Hence, we considered the information available from these single clinical trials insufficient to use in the model. Consequently, we considered the consultation of an expert panel (from within the Dutch context) superior to using data from multiple international trials.

Hence, transition rate estimates were attained from consultation with a Delphi panel of experts (Table 1). We retrieved all transition rate estimates from one consistent source (i.e., the expert panel).

The consulted psychiatrists suggested that the group of patients suboptimally treated with IR would, in particular, 
experience practical problems with accurate medication intake schemes during the day or at school. These patients would need to put more effort into adherence to the administration scheme compared with OROS, for which administration is limited to once a day. These differences in effect and effort were reflected in the transition rates between states.

Transition estimates were attained by blind questionnaires in two rounds, according to Dutch guidelines for pharmacoeconomic research [30] and consistent with the Delphi panel method [51, 52]. The experts were consulted independently and were not aware of the identity of the other experts joining the panel. Before distributing the questions to the experts, it was decided that consensus was supposed to be reached after two rounds of answers when (a) feedback of the experts was clear and (b) when experts did not all change their answers on the basis of the mean of the feedback of the first round. The questions for the panel were sent and returned by email. One of the researchers registered the replies anonymously. After all experts had returned the questionnaires, their answers were combined. The mean value for each question constituted the basis for the final answer to each question. The proposals for the final answers as well as the anonymized individual answers of the participants were reported to the experts after round 1 . In the second round, experts were asked whether they intended to change their previous answers on the basis of the proposal for the final answer.

\subsection{Utility Values}

ADHD is associated with reduced health-related quality of life [53-56]. The present model was built to assess the cost utility of OROS versus IR in children and adolescents with ADHD. Effects were expressed in terms of quality-adjusted life-years (QALYs). Several members of our research team were involved in a recent Dutch study that measured the quality of life of children with ADHD and their parents [57]. The study of van der Kolk et al. [57] was a cross-sectional study among member of a Dutch ADHD parent association. Data collection occurred via online questionnaires. The quality of life of the children $(n=618)$ was based on parent proxy ratings, and the quality of life of the caregivers $(n=590)$ was based on self-report of the Euroqol (EQ-5D) questionnaire $[57,58]$. The available quality of life data were highly suitable for inclusion in the current model as the state definitions of responders and non-responders closely matched the definition within the current model.

\subsubsection{Utility of the Patient}

We found a significant difference in quality of life of patients compliant with prescribed medication compared with that of non-compliant patients [57]. Compliant patients reported a quality of life of 0.84 (ages 8-12 years 0.82 ; ages $13-18$ years 0.86 ) whereas non-compliant patients reported a quality of life of 0.75 (ages 8-12 years 0.74 ; ages $13-18$ years 0.77 ) [57]. In the current model, we included the quality of life values of the compliant group for the state 'optimal' and the utilities of the non-compliant group for the state of 'suboptimal' functioning. As there was no utility available for patients who had stopped treatment, we considered it reasonable to assign to those patients the same utility as patients in the suboptimal state, as this would constitute a conservative estimate. Based on the available data, utility was modeled to differ per model state but not per treatment type.

\subsubsection{Spillover Effects on Caregiver}

Family effects $[8,59-62]$ and negative effects of ADHD on families in particular [26, 63] have been addressed several times in the literature. Le et al. [8] suggested that benefits of ADHD treatment may also extend further than the individual patient. Brouwer et al. [19] proposed that when taking a societal perspective, these effects may be added to the effects experienced by patients. Hence, we considered it valuable to include spillover effects on the utility of a parent in the model. In our recent study on quality of life [57], we found a significant correlation between the quality of life of the child and the caregiver. No significant difference was found between the quality of life of parents of compliant or non-compliant children.

The literature on ADHD is very limited on this aspect, and our study [57] was the first study to report utilities of patients with ADHD and caregivers in one study. Further studies on the specific effect of ADHD on caregiver utility could not be retrieved from the literature. However, there is evidence available on the effect of a child with ADHD on health expenditures of caregivers. Hakkaart et al. [4] stated that $25 \%$ of the health care expenditures of the caregiver of a child with ADHD can be attributed to the behavioral problems of the child. This suggests a considerable influence of child health on caregiver health. In the absence of more specific data on the caregiver effects of ADHD, we searched for publications on caregiver effects in other diseases. Evidence from the literature on meningitis [23] suggests that 'spillover' health effects on family may constitute as much as $48 \%$ of the health effects on the patient. In the case of ADHD, this may be a conservative estimate as ADHD has been found to be especially stressful on the direct environment of the patient. Hence, as an estimate, we included $48 \%$ of caregiver utility in the model. 


\subsection{Cost Parameters}

Categories of direct medical and non-medical costs were kept consistent with the Faber model [29]. These categories were medication costs, costs of medical consultations, costs of medical and non-medical interventions, and costs of special education. Costs differed per state, and in remission, we assumed no costs associated with ADHD. We assumed all costs except drug costs to be only dependent on the state and not on the type of medication (IR or OROS) received by the patient. This assumption was based on evidence from the literature on comparable efficacy of IR and OROS under the provision of full therapy compliance [10-12] and was confirmed by the expert panel of psychiatrists (Table 1). We considered different costs for patients when below the age of 12 years and at and above the age of 12 years. This modeled difference in costs according to current age was based on consultation of the expert panel (Table 1). The experts suggested differences in cost when switching schools (i.e., from primary to secondary education), which corresponds to the age of 12 years in the Dutch setting. Health care consumption (i.e., frequencies of consultations and non-pharmacological interventions) were extracted from the study performed by Faber et al. [29]. All costs were valued in euros $(€ ; 2014)$. Cost prices were updated based on Hakkaart et al. [64], costs of special education were updated as reported by the Dutch Ministry of Education [65] and all costs were adjusted to 2014 values.

Next to the cost categories consistent with the Faber model [29], literature and available data of additional cost categories were searched to determine relevance and feasibility of inclusion in the model. Considered categories were criminal justice costs, costs of lower-proficiency work and low income, out-of pocket expenses and spillover effects on caregivers (i.e., health care costs and production losses).

\subsubsection{Costs of Medication}

Individuals in the OROS arm of the model used a full daily dose of OROS per day in the optimal state and no medication in all other states. In the IR arm of the study, participants were assumed to take the full daily dose of IR a day in the optimal state and on average $1 / 3$ of the daily dose in the suboptimal state. The daily dose of both OROS and IR was determined on the basis of the average daily dose of two age groups (6-12 and 13-18 years) and was based on IMS health data [66]. Cost of medication was based on the Dutch price list [67].

\subsubsection{Costs of Medical Consultations}

Consultation costs concerned contacts with psychiatrists, other medical specialists, general practitioners, and crisis contacts. The number of visits per year was dependent on age and based on the Faber model [29]. Unit prices were retrieved from the Dutch manual for costing research [64] and applied to the number of contacts.

\subsubsection{Costs of Medical and Non-medical Interventions}

Intervention costs included costs of psychosocial and psychotherapeutic interventions as well as interventions for educational support (i.e., psycho education, parent training, behavior child therapy, social skills training, teacher training, remedial teaching, physical therapy, home training/care, outpatients' treatment and institutionalization). These categories were in line with the Dutch clinical guidelines for ADHD [9]. Interventions that are provided on a limited scale in the Netherlands (i.e., neurofeedback, cognitive training, mindfulness, diet) have not been included. The number of contacts was based on the Faber model [29]. Intervention costs were assumed to occur at age 6 and at age 12 for 1 year each as experts from the panel of consulted psychiatrists (Table 1) indicated that those costs mainly occurred at the moment of switching between schools. Unit prices were retrieved from the Dutch manual for costing research [64] and applied to the number of contacts.

\subsubsection{Costs of Special Education}

Costs for special education were additional costs per day in special education. Advice for placement in special education was assumed dependent on age. Costs for special education were considered continuous from age 6 to age 18 in accordance with the experts' opinion. Probability of placement was based on the Faber model [29], and unit prices were based on the Ministry of Education, Culture and Science [65].

\subsubsection{Criminal Justice Costs}

Several authors have found a positive relationship between ADHD in childhood and antisocial behavior and drug use in (young) adults [68-70]. However, it has to be taken into account that the high degree of antisocial activity may be attributed to comorbid conduct disorder [71]. A recent study by Lichtenstein et al. [72] suggested that criminal behavior of ADHD patients decreases when medication is taken consistently. Evidence from the literature suggests 
that data on criminal justice costs related to ADHD are scarce [20] and especially limited in the European context [8]. Though these costs are considered highly relevant especially in the light of a possible relation with medication intake, the lack of available data resulted in the exclusion of these costs from the current model.

\subsubsection{Costs for Educational Support, Cost of Lower- Proficiency Work and Low Income}

Evidence from literature suggests that the impact of ADHD may exceed the age of school-going children and that it may result in poor educational performance $[4,8,63,73$, 74], work achievements [75, 76] and household income $[20,70,77,78]$. However, it is not yet clear whether medical treatment necessarily improves academic performance or income, as it may have an effect on some aspects of academic functioning and not on others [73]. Children with ADHD often require additional support within the educational setting [20]. As this study focused on children between 6 and 18 years, the costs of additional educational support within the education system up to age 18 were included within the cost categories 'costs of medical and non-medical interventions' and 'costs of special education' in the model (i.e., costs for teacher training, remedial teaching and costs of special education). When expanding current projections to a lifetime perspective, long-term consequences of educational effects (i.e., on work and income) should be included as well.

\subsubsection{Out-of-Pocket Expenses}

In a Dutch study on out-of-pocket expenses of children and adolescents with ADHD, Hakkaart et al. [4] presented data from parents of children with ADHD treated by a pediatrician. The authors found out-of-pocket expenses of $€ 23.13$ (standard deviation $€ 150.35$; adjusted to $2014 €$ ) per annum in the Dutch setting. As the amount of out-of-pocket expenses is negligible (i.e., not significantly different from zero) in the study by Hakkaart et al. [4], we did not include these expenses in the current model.

\subsubsection{Spillover on Caregivers (Medical Costs and Production Losses)}

Hakkaart et al. [4] found that mean health care costs of mothers of children with ADHD were significantly higher than those of mothers of healthy children. Mean medical costs per year were $€ 841.93$ (adjusted to $2014 €$ ) for mothers of children with ADHD compared with $€ 178.10$ of mothers of a healthy child. The authors stated that $25 \%$ of mothers noted that their use of health care services was related to the behavioral problems of their child [4].
Consequently, we assumed health care costs for a caregiver of $0.25 \times(€ 841.93-178.10)$ in the suboptimal and treatment stopped states and included these costs in the model. In the optimal state, no additional costs were assigned.

Hakkaart et al. [4] also collected data on production losses of mothers of patients with ADHD. The authors found significantly higher production losses in mothers of children with ADHD compared with mothers of healthy controls. Mean annual production losses of mothers (reduced efficiency and absence from work) were $€ 2594.03$ (adjusted to $2014 €$ ) compared with $€ 779.48$ for mothers of healthy children. As noted above, Hakkaart et al. [4] found that $25 \%$ of health care costs of the mother were related to behavioral problems of the child. It seems reasonable to assume that also $25 \%$ of production losses can be attributed to the behavioral problems of the child. Hence, in the model, we included mean annual production losses of $0.25 \times(€ 2594.03-779.48)$ in the suboptimal and treatment stopped states. In the optimal state, no additional costs were assigned.

\subsection{Model Validation}

Face validity was ascertained by consulting experts in the field of ADHD in the Netherlands on clinical aspects of model structure, model parameters and model input. Furthermore, verification of transition rates was attempted. Because of the scarce available data, we could only globally verify the number of patients in an optimal state after 1 year with response percentages from the literature identified from the systematic review [48-50], which we performed as part of the search for suitable transition rates. Though the estimates within these studies were based on different definitions of response or improvement and studies were performed in different countries, this constituted the best available data. As our study was performed in the population of patients who had in the past been treated with IR and reacted suboptimally because of problems with medication intake, it was expected that overall response within the existing literature would be higher than in our model. This rationale was supported, as Garg et al. [49] reported a $91 \%$ treatment response in patients treated with MPH, Sobanski et al. [48] found $78 \%$ of patients receiving combined short- and long-acting MPH treatment had reduced symptoms and, according to Soutullo et al. [50], $51 \%$ of patients responded to treatment with OROS. On the basis of the expert panel estimates within the current model, $22 \%$ of patients treated with IR and $36 \%$ of patients treated with OROS achieved a transition from a suboptimal to an optimal state after 1 year. Hence, the transition estimates in our model appear to be in line with expectations and may even be 
conservative. We further performed scenario analyses to examine the sensitivity of model results to these parameters.

\subsection{Sensitivity Analyses}

Sensitivity analyses were performed for four scenarios: one scenario assuming equal transition rates for IR and OROS; a second scenario including an augmented daily dose of exposure to medication; a third scenario excluding medical costs and production losses of the caregiver; and a forth scenario excluding the utility of caregivers. As transition rates were based on expert opinion (Table 4), we performed a scenario to estimate the impact of these parameters on the results. Furthermore, due to issues of noncompliance, the daily dose data may provide an underestimation of optimal exposure. To measure the effect of this potential bias, a scenario was estimated which corrected for noncompliance. Studies by Adler and Nierenberg [16] and Swanson [79] have estimated noncompliance to amount to 13-64\% and $20-65 \%$, respectively. On the basis of these findings, the scenario considered an average of $40 \%$ noncompliance in daily dose data used (implying augmentation of the daily dose by $67 \%$ for both treatment arms). Two additional scenarios were performed to estimate the effect of the caregiver costs and effects on the model outcomes. As the underlying data for the inclusion of these model components were limited, the outcomes of the scenario analysis may provide further incentive for future data collections. One scenario was performed excluding medical costs and production losses of caregivers, and another scenario was performed where utilities of caregivers were excluded. Monte Carlo results were simulated per scenario, allowing for uncertainty around all parameter estimates while analyzing the specific effect of changes of the parameters of interest. Detailed model parameters are provided in Table 4.

\section{Results}

\subsection{Transition Estimates}

In accordance with the model population, the expert panel of psychiatrists (Table 1) estimated transition rates for a patient population initially treated with IR with suboptimal results because of incorrect intake of medication.

Table 5 displays mean transition percentages per day as estimated by the expert panel.

Variability in cost parameters was captured by gamma distributions around the mean, and variability in transition probabilities entered the model through Dirichlet distributions [33]. Samples from these prior distributions were drawn by Monte Carlo simulation. For illustrative purposes and in the absence of trial data, as a common simplifying assumption, the standard errors of the cost parameters were assumed $20 \%$ of the mean. As is common in probabilistic models, a total of 1000 Monte Carlo simulations were performed to generate the model results.

Different estimates were attained for patients receiving OROS and for patients receiving IR. Experts estimated the probability to transfer from a suboptimal or treatment stopped state to an optimal state to be higher for patients receiving OROS than for patients receiving IR. However, they predicted patients receiving OROS to have a lower chance of staying in an optimal state than patients receiving IR. Furthermore, the experts estimated patients receiving OROS to have a lower chance than patients receiving IR to stop treatment and a higher chance to go back to an optimal or suboptimal state when having stopped the treatment. Transitions from the suboptimal state to the remaining states appear to differ most between treatments. All experts considered the transition to a state of remission to be $0 \%$ per day. This means that the state 'remission' becomes redundant. In line with earlier critical comments on possible relapse after remission, it becomes clear that remission is seen as an exceptionally rare state (Fig. 3) such that patients are expected to keep moving between the optimal, suboptimal and treatment stopped states instead of reaching a stable state of remission.

\subsection{Model Results and Sensitivity Analyses}

Model results indicate dominance of OROS compared with IR in this population. OROS results in incremental QALY gains while saving costs. The number of QALYs for OROS exceeds the number of QALYs for IR by 0.22 (95\% CI $-0.206,0.228$ ), and the total costs of OROS are estimated to be lower than IR, with incremental cost savings of $€ 5815$ (95\% CI 5661-5969) (Table 6). These results suggest that, for this patient group, OROS produces better effects at lower cost compared with IR. The detailed probabilistic model results of 1000 Monte Carlo simulations are presented on a cost-effectiveness $(\mathrm{C} / \mathrm{E})$ plane and as a cost-effectiveness acceptability curve (CEAC) [80] in Figs. 4 and 5, respectively. Figure 4 provides details on the uncertainty around the costs and effect of OROS compared with IR. The 1000 points in the scatter plot each represent one simulation result. The $x$-axis displays the amount of incremental QALY gains or losses and the $y$-axis shows the incremental costs expressed in euros.

The results of the $\mathrm{C} / \mathrm{E}$ plane show that the majority of data points appear in the southeast quadrant, with lower costs and higher effects of OROS compared with IR, which indicates dominance of OROS versus IR. 
Table 4 Detailed model parameters and assumptions (in $2014 €$ )

\begin{tabular}{|c|c|c|}
\hline Parameter & Description & Source \\
\hline \multicolumn{3}{|l|}{ General parameters } \\
\hline Discount rate & $\begin{array}{l}\text { Costs discounted at constant } \\
\text { discount rate of } 4 \% \text {, effects at constant } \\
\text { discount rate of } 1.5 \%\end{array}$ & College voor Zorgverzekeringen [30] \\
\hline Patient age & $\begin{array}{l}\text { All patients assumed to enter } \\
\text { the model at age } 6\end{array}$ & $\begin{array}{l}\text { Indicatie Concerta, Landelijke Stuurgroep } \\
\text { Multidisciplinaire Richtlijnontwikkeling } \\
\text { in de GGZ [9] }\end{array}$ \\
\hline Monte Carlo random sampling & $N=1000$ & Briggs et al. [33] \\
\hline \multicolumn{3}{|l|}{ Transition probabilities } \\
\hline IR: A to A & Dirichlet, mean 8.97 & Expert panel data \\
\hline IR: A to $B$ & Dirichlet, mean 90.20 & Expert panel data \\
\hline IR: A to $\mathrm{C}$ & Dirichlet, mean 1.01 & Expert panel data \\
\hline IR: A to D & 0 & Expert panel data \\
\hline IR: $\mathrm{B}$ to $\mathrm{A}$ & Dirichlet, mean 22.47 & Expert panel data \\
\hline IR: $\mathrm{B}$ to $\mathrm{B}$ & Dirichlet, mean 54.25 & Expert panel data \\
\hline IR: $\mathrm{B}$ to $\mathrm{C}$ & Dirichlet, mean 23.28 & Expert panel data \\
\hline IR: $B$ to $D$ & 0 & Expert panel data \\
\hline IR: $\mathrm{C}$ to $\mathrm{A}$ & Dirichlet, mean 16.58 & Expert panel data \\
\hline IR: $\mathrm{C}$ to $\mathrm{B}$ & Dirichlet, mean 10.26 & Expert panel data \\
\hline IR: $\mathrm{C}$ to $\mathrm{C}$ & Dirichlet, mean 73.16 & Expert panel data \\
\hline IR: $\mathrm{C}$ to $\mathrm{D}$ & 0 & Expert panel data \\
\hline OROS: A to A & Dirichlet, mean 6.25 & Expert panel data \\
\hline OROS: A to B & Dirichlet, mean 93.75 & Expert panel data \\
\hline OROS: A to C & 0 & Expert panel data \\
\hline OROS: A to D & 0 & Expert panel data \\
\hline OROS: $\mathrm{B}$ to $\mathrm{A}$ & Dirichlet, mean 58.91 & Expert panel data \\
\hline OROS: $\mathrm{B}$ to $\mathrm{B}$ & Dirichlet, mean 23.81 & Expert panel data \\
\hline OROS: $\mathrm{B}$ to $\mathrm{C}$ & Dirichlet, mean 17.27 & Expert panel data \\
\hline OROS: B to D & 0 & Expert panel data \\
\hline OROS: $\mathrm{C}$ to $\mathrm{A}$ & Dirichlet, mean 24.21 & Expert panel data \\
\hline OROS: $\mathrm{C}$ to $\mathrm{B}$ & Dirichlet, mean 14.21 & Expert panel data \\
\hline OROS: $\mathrm{C}$ to $\mathrm{C}$ & Dirichlet, mean 61.58 & Expert panel data \\
\hline OROS: $\mathrm{C}$ to $\mathrm{D}$ & 0 & Expert panel data \\
\hline \multicolumn{3}{|l|}{ Utility: patient ( $8-12$ years) } \\
\hline Optimal & Beta, mean 0.82 , se 0.0979 & van der Kolk et al. [57] \\
\hline Suboptimal & Beta, mean 0.74 , se 0.01588 & van der Kolk et al. [57] \\
\hline Treatment stopped & Beta, mean 0.74 , se 0.01588 & van der Kolk et al. [57] \\
\hline \multicolumn{3}{|l|}{ Utility: patient (13-18 years) } \\
\hline Optimal & Beta, mean 0.86 , se 0.01097 & van der Kolk et al. [57] \\
\hline Suboptimal & Beta, mean 0.77 , se 0.02645 & van der Kolk et al. [57] \\
\hline Treatment stopped & Beta, mean 0.77 , se 0.02645 & van der Kolk et al. [57] \\
\hline \multicolumn{3}{|l|}{ Utility: caregiver } \\
\hline Optimal & Beta, mean 0.85 , se 0.00897 & van der Kolk et al. [57] \\
\hline Suboptimal & Beta, mean 0.83 , se 0.01499 & van der Kolk et al. [57] \\
\hline Treatment stopped & Beta, mean 0.83 , se 0.01499 & van der Kolk et al. [57] \\
\hline \multicolumn{3}{|l|}{ Drug costs } \\
\hline Daily dose OROS: child 6-12 years (mg) & 31.70 & IMS Health BV [66] \\
\hline Daily dose OROS: child $13-18$ years (mg) & 39.10 & IMS Health BV [66] \\
\hline Daily dose IR: child 6-12 years (mg) & 22.00 & IMS Health BV [66] \\
\hline
\end{tabular}


Table 4 continued

\begin{tabular}{|c|c|c|c|c|}
\hline Parameter & \multicolumn{3}{|c|}{ Description } & Source \\
\hline Daily dose IR: child $13-18$ years (mg) & \multicolumn{3}{|l|}{29.20} & IMS Health BV [66] \\
\hline Costs/mg OROS & \multicolumn{3}{|l|}{0.05} & Zorginstituut Nederland [67] \\
\hline Costs/mg IR & \multicolumn{3}{|l|}{0.01} & Zorginstituut Nederland [67] \\
\hline Pharmacy fee/ 3 months & \multicolumn{3}{|l|}{7.0} & Zorginstituut Nederland [67] \\
\hline Consultation costs & \multicolumn{4}{|c|}{$\begin{array}{l}\text { Incurred by children between } 6 \text { and } \\
18 \text { years of age }\end{array}$} \\
\hline Number of visits per year: child $\leq 12$ & State A & State B & State C & \\
\hline Psychiatrist & 2.28 & 3.42 & 5.00 & Faber et al. [29] \\
\hline Other specialist & 0 & 0 & 1.38 & Faber et al. [29] \\
\hline General practitioner & 0 & 0 & 0.58 & Faber et al. [29] \\
\hline Crisis contacts & 0.57 & 1.49 & 2.71 & Faber et al. [29] \\
\hline Number of visits per year: child $>12$ & State A & State B & State C & \\
\hline Psychiatrist & 2.43 & 3.57 & 5.00 & Faber et al. [29] \\
\hline Other specialist & 0 & 0 & 0.11 & Faber et al. [29] \\
\hline General practitioner & 0 & 0.29 & 0.43 & Faber et al. [29] \\
\hline Crisis contacts & 0.35 & 1.28 & 3.00 & Faber et al. [29] \\
\hline \multicolumn{5}{|l|}{ Costs per visit } \\
\hline Psychiatrist & \multicolumn{3}{|l|}{113.53} & Hakkaart et al. [64] \\
\hline Other specialist & \multicolumn{3}{|l|}{75.15} & $\begin{array}{l}\text { Weighted average psychiatrist and } \\
\text { medical specialist: } 46: 34[29,64]\end{array}$ \\
\hline General practitioner & \multicolumn{3}{|l|}{31.22} & Hakkaart et al. [64] \\
\hline Crisis contacts & \multicolumn{3}{|l|}{256.20} & $\begin{array}{l}\text { Based on Tariffs AWBZ-institutions } \\
2005 \text { [88] }\end{array}$ \\
\hline Intervention costs & \multicolumn{4}{|c|}{ Incurred by children aged 6 and 12 years } \\
\hline Transferred $\%$ of patients: child $\leq 12$ & State A & State B & State C & \\
\hline Psycho education & 0.89 & 0.93 & 1.00 & Faber et al. [29] \\
\hline Parent training & 0.49 & 0.76 & 0.79 & Faber et al. [29] \\
\hline Behavior therapy child & 0.07 & 0.23 & 0.57 & Faber et al. [29] \\
\hline Social skills training (SOVA) & 0.19 & 0.28 & 0.38 & Faber et al. [29] \\
\hline Teacher training & 0.43 & 0.57 & 0.66 & Faber et al. [29] \\
\hline Remedial teaching & 0.37 & 0.51 & 0.77 & Faber et al. [29] \\
\hline Physical therapy & 0 & 0 & 0 & Faber et al. [29] \\
\hline Home training/care & 0.04 & 0.13 & 0.33 & Faber et al. [29] \\
\hline Outpatients' treatment & 0 & 0 & 0.25 & Faber et al. [29] \\
\hline Institutionalization & 0 & 0 & 0.03 & Faber et al. [29] \\
\hline Transferred $\%$ of patients: child $>12$ & State A & State B & State C & \\
\hline Psycho education & 0.94 & 0.90 & 0.89 & Faber et al. [29] \\
\hline Parent training & 0.31 & 0.44 & 0.74 & Faber et al. [29] \\
\hline Behavior therapy child & 0.09 & 0.28 & 0.56 & Faber et al. [29] \\
\hline Social skills training (SOVA) & 0.07 & 0.26 & 0.53 & Faber et al. [29] \\
\hline Teacher training & 0.10 & 0.33 & 0.32 & Faber et al. [29] \\
\hline Remedial teaching & 0.02 & 0.39 & 0.47 & Faber et al. [29] \\
\hline Physical therapy & 0 & 0 & 0 & Faber et al. [29] \\
\hline Home training/care & 0 & 0.1 & 0.13 & Faber et al. [29] \\
\hline Outpatients' treatment & 0 & 0 & 0.26 & Faber et al. [29] \\
\hline Institutionalization & 0 & 0 & 0.04 & Faber et al. [29] \\
\hline Number of visits per year: child $\leq 12$ & State A & State B & State C & \\
\hline Psycho education & 2.64 & 3.64 & 3.86 & Faber et al. [29] \\
\hline Parent training & 8.34 & 7.92 & 14.01 & Faber et al. [29] \\
\hline
\end{tabular}


Table 4 continued

\begin{tabular}{|c|c|c|c|c|}
\hline \multirow{2}{*}{$\frac{\text { Parameter }}{\text { Behavior therapy child }}$} & \multicolumn{3}{|c|}{ Description } & \multirow{2}{*}{$\begin{array}{l}\text { Source } \\
\text { Faber et al. [29] }\end{array}$} \\
\hline & 13.18 & 11.80 & 13.15 & \\
\hline Social skills training (SOVA) & 9.15 & 9.79 & 9.15 & Faber et al. [29] \\
\hline Teacher training & 1.75 & 3.73 & 3.94 & Faber et al. [29] \\
\hline Remedial teaching & 20.00 & 20.00 & 20.00 & Faber et al. [29] \\
\hline Physical therapy & 6.00 & 0 & 0 & Faber et al. [29] \\
\hline Home training/care & 10.00 & 11.15 & 14.31 & Faber et al. [29] \\
\hline Outpatients' treatment & 0 & 0 & 51.75 & Faber et al. [29] \\
\hline Institutionalization & 0 & 0 & 90.00 & Faber et al. [29] \\
\hline Number of visits per year: child $>12$ & State A & State B & State C & \\
\hline Psycho education & 2.78 & 3.57 & 5.42 & Faber et al. [29] \\
\hline Parent training & 5.91 & 8.24 & 13.74 & Faber et al. [29] \\
\hline Behavior therapy child & 10.00 & 11.44 & 12.88 & Faber et al. [29] \\
\hline Social skills training (SOVA) & 9.15 & 11.44 & 10.59 & Faber et al. [29] \\
\hline Teacher training & 2.00 & 2.50 & 3.73 & Faber et al. [29] \\
\hline Remedial teaching & 20.00 & 20.00 & 20.00 & Faber et al. [29] \\
\hline Physical therapy & 0 & 0 & 0 & Faber et al. [29] \\
\hline Home training/care & 0 & 10.00 & 10.06 & Faber et al. [29] \\
\hline Outpatients' treatment & 0 & 0 & 51.75 & Faber et al. [29] \\
\hline Institutionalization & 0 & 0 & 135.00 & Faber et al. [29] \\
\hline \multicolumn{5}{|l|}{ Costs per visit } \\
\hline Psycho education & \multicolumn{3}{|l|}{111.17} & $\begin{array}{l}\text { Based on Tariffs AWBZ-institutions } \\
2005 \text { [88] }\end{array}$ \\
\hline Parent training & \multicolumn{3}{|l|}{104.15} & $\begin{array}{l}\text { Based on Tariffs AWBZ-institutions } \\
2005 \text { [88] }\end{array}$ \\
\hline Behavior therapy child & \multicolumn{3}{|l|}{111.17} & $\begin{array}{l}\text { Based on Tariffs AWBZ-institutions } \\
2005 \text { [88] }\end{array}$ \\
\hline Social skills training (SOVA) & \multicolumn{3}{|l|}{111.17} & $\begin{array}{l}\text { Based on Tariffs AWBZ-institutions } \\
2005 \text { [88] }\end{array}$ \\
\hline Teacher training & \multicolumn{3}{|l|}{76.05} & $\begin{array}{l}\text { Based on Tariffs AWBZ-institutions } \\
2005 \text { [88] }\end{array}$ \\
\hline Remedial teaching & \multicolumn{3}{|l|}{58.49} & $\begin{array}{l}\text { Based on Dutch Society of Remedial } \\
\text { Teachers [89] }\end{array}$ \\
\hline Physical therapy & \multicolumn{3}{|l|}{39.84} & Hakkaart et al. [64] \\
\hline Home training/care & \multicolumn{3}{|l|}{114.52} & Based on Health care insurance board [90] \\
\hline Outpatients' treatment & \multicolumn{3}{|l|}{150.57} & Hakkaart et al. [64] \\
\hline Institutionalization & \multicolumn{3}{|l|}{301.09} & Hakkaart et al. [64] \\
\hline \multirow[t]{2}{*}{ Special education costs } & \multicolumn{4}{|c|}{$\begin{array}{l}\text { Incurred by children between } 6 \text { and } \\
18 \text { years of age }\end{array}$} \\
\hline & State A & State B & State C & \\
\hline Advice placement special education $(\%)$ : child $\leq 12$ & 0.015 & 0.1224 & 0.4356 & Faber et al. [29] \\
\hline Advice placement special education $(\%)$ : child $>12$ & 0.0007 & 0.0863 & 0.3711 & Faber et al. [29] \\
\hline Additional costs special education/day & 13.63 & & & $\begin{array}{l}\text { Based on Ministry of Education, } \\
\text { Culture and Science [65] }\end{array}$ \\
\hline
\end{tabular}

$I R$ immediate-release, OROS osmotic-release oral system, $S E$ standard error

Figure 5 shows a graphical presentation of the CEAC, displaying the probability that OROS is cost effective compared with IR given different values of maximum threshold for society. The threshold values in terms of euros are shown on the $x$-axis and the probability of OROS being cost effective is displayed on the $y$-axis.

The CEAC displays data points within all four quadrants, with the majority of data points in the southeast 
Table 5 Mean (standard deviation) transitions per day (in \%) as estimated by expert panel

\begin{tabular}{|c|c|c|c|c|}
\hline From/to & Optimal & Suboptimal & Treatment stopped & Remission \\
\hline \multicolumn{5}{|l|}{ IR } \\
\hline Optimal & $8.79(6.34)$ & $90.20(7.84)$ & $1.01(2.02)$ & $0(0)$ \\
\hline Suboptimal & $22.47(21.41)$ & $54.25(14.21)$ & 23.28 (11.74) & $0(0)$ \\
\hline Treatment stopped & $16.58(8.02)$ & $10.26(8.60)$ & $73.16(15.94)$ & $0(0)$ \\
\hline \multicolumn{5}{|l|}{ OROS } \\
\hline Optimal & $6.25(9.46)$ & $93.75(9.46)$ & $0(0)$ & $0(0)$ \\
\hline Suboptimal & $58.91(21.03)$ & $23.81(12.51)$ & $17.27(9.82)$ & $0(0)$ \\
\hline Treatment stopped & $24.21(11.73)$ & $14.21(15.81)$ & $61.58(23.98)$ & $0(0)$ \\
\hline
\end{tabular}

IR immediate-release, OROS osmotic-release oral system

Fig. 3 Expert comments on state of remission. $A D H D$ attention deficit hyperactivity disorder

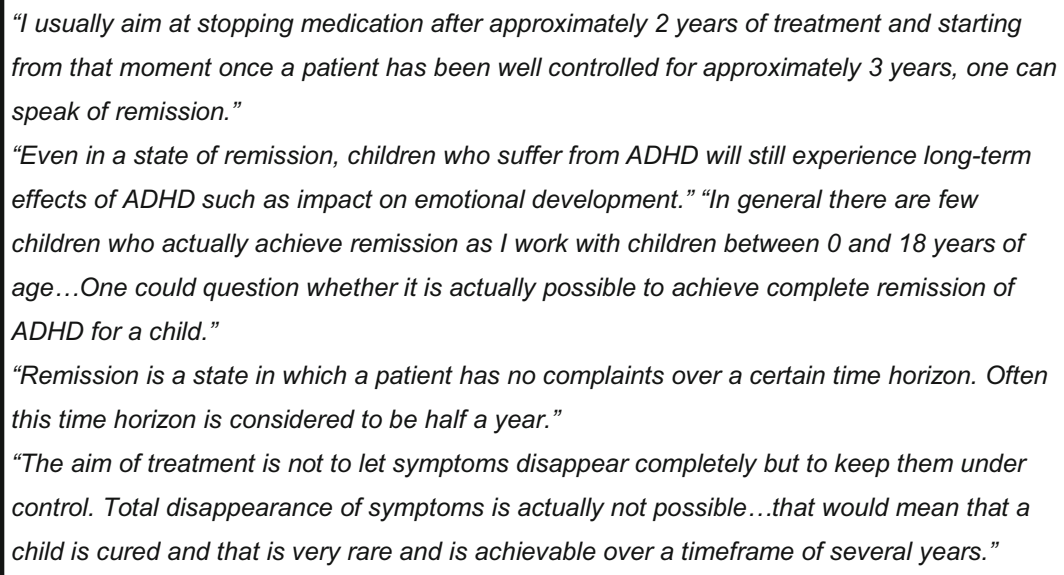

quadrant [81]. The probability of OROS being cost effective ranges between 93 and $99 \%$. The CEAC does not cross the $y$-axis at 0 as some data points in the $\mathrm{C} / \mathrm{E}$ plane display cost savings of OROS compared with IR. Furthermore, the CEAC does not asymptote to 1 because a part of the observed data points on the $\mathrm{C} / \mathrm{E}$ plane show negative incremental effects.

Sensitivity analyses indicate that when transition rates of OROS are equal to the transitions of IR (scenario 1), the incremental QALYs gained for OROS compared with IR amount to 0.00 and costs of treatment with OROS appear slightly higher than treatment with IR, with additional incremental costs of $€ 800$ (Table 6). These results in terms of incremental costs are close to the results of the Faber model [29], and the incremental effects are reduced to zero. Model results, thus, are strongly dependent on accurate estimates of transition probabilities as these determine how fast patients move between model states and, hence, how often they stay in more or less 'expensive' states.

The scenario with an augmented daily dose of exposure to medication (scenario 2) resulted in slightly lower savings compared with the base scenario (savings of $€ 4502$ and QALY gains of 0.21).
Exclusion of medical costs and production losses of caregivers from the model results in incremental cost savings of $€ 4930$ and incremental QALY gains of 0.22 .

When utility of caregivers is excluded, there are insignificant changes in incremental costs (€5900) and a decrease in incremental QALY gains to 0.15 . This incremental QALY decrease is explained by the fact that $48 \%$ of the QALYs of the patient have been added to account for effect on a caregiver.

\section{Discussion and Conclusions}

Policymakers increasingly use cost-effectiveness analyses to inform decision making on competing health care interventions. Health economic models facilitate these analyses by providing a framework to combine information from different sources and enable probabilistic estimations. Within health care there has been debate on which perspective to take in such models. In the Netherlands, a societal perspective is common according to the health economic guidelines. Lately, there have been voices to even include broader effects (i.e., exceeding the patient and 
Table 6 Mean model results and sensitivity analyses of Monte Carlo simulations $(n=1000)$

\begin{tabular}{llcc}
\hline & Description & Incremental costs (2014 €) & Incremental QALYs \\
\hline Base case & & -5815 & 0.22 \\
Scenario 1 & Transition rates of OROS equal to transition rates of IR & 800 & 0.00 \\
Scenario 2 & Daily dose of medication +66 \% & -4502 & 0.21 \\
Scenario 3 & Medical costs and production losses of caregiver excluded & -4930 & 0.22 \\
Scenario 4 & Utility of caregivers excluded & -5900 & 0.15 \\
\hline
\end{tabular}

$I R$ immediate-release, OROS osmotic-release oral system, $Q A L Y$ quality-adjusted life-year

Fig. 4 Scatter plot: incremental Monte Carlo simulations. $C / E$ cost-effectiveness, $Q A L Y$ quality-adjusted life-year costs and effects based on 1000

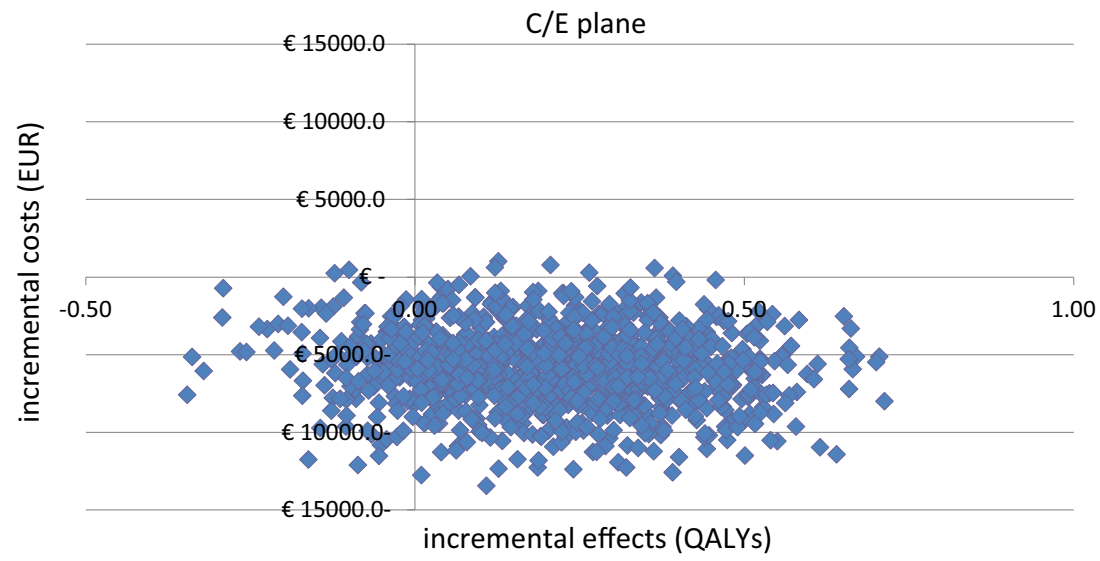

Fig. 5 CEAC: probability of OROS being cost effective compared with IR. CEAC costeffectiveness acceptability curve, $I R$ immediate-release, OROS osmotic-release oral system

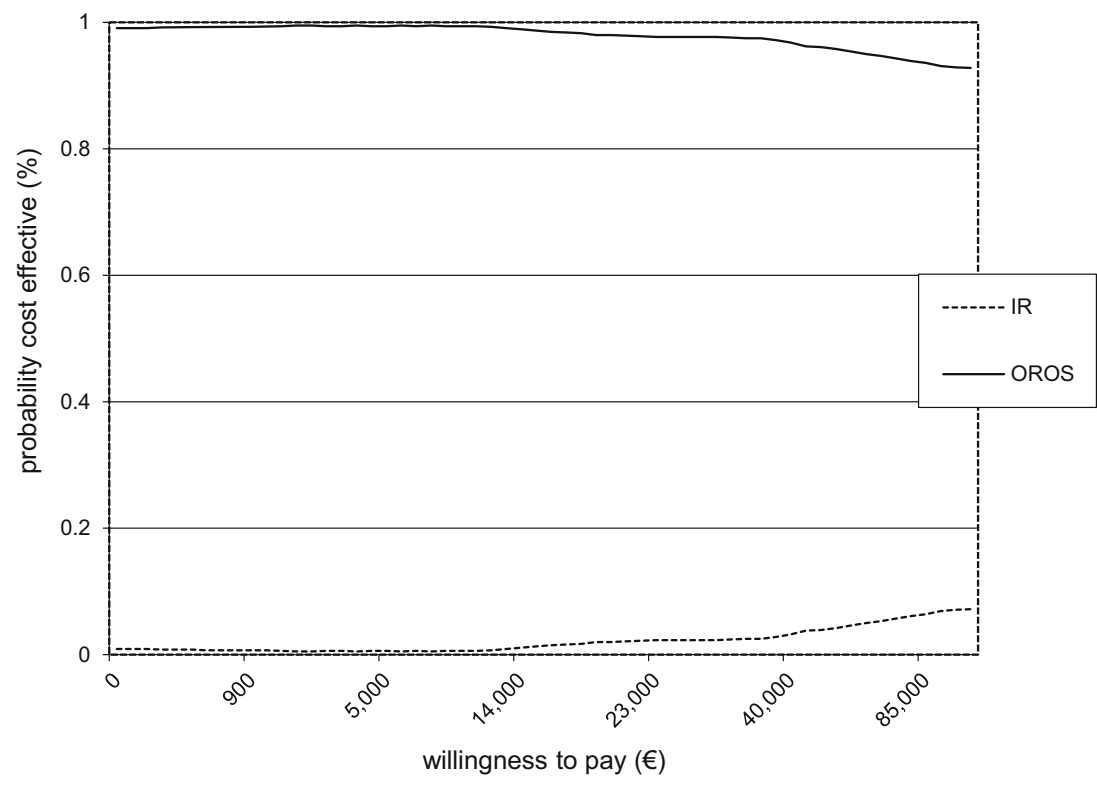

exceeding health care) [19]. This may be especially relevant to illness in children and disorders, which have a high impact on third parties (such as in the setting of ADHD). The presented model adds to the current movement towards broader considerations in cost-effectiveness analyses. We have presented a model compliant with the current health economic guidelines and at the same time considered, and where possible included, broader societal aspects to increase the comprehensiveness of the model results. Hence, the results of this study can be used as direct input to policymakers' decision making.

Model results indicate that, for children responding suboptimally to treatment with IR, the beneficial effect of OROS on compliance may be worth the additional medication costs. The current model was based on the Faber model [29], but model structure and input were improved and the model was enhanced with additional broader societal parameters. Transition rates consistent 
with our model structure could not be obtained from one source of literature. Therefore, we chose to consult an expert panel to provide transition rate estimates for all model states. Guidelines for health economic analysis state that in the case where data are not available, the use of input from an expert panel is accepted, provided that a scientific method is used. The experts were consulted using a Delphi method as described in the Dutch guidelines for pharmacoeconomic analyses [30]. In the case of transition probabilities, the use of an expert panel was crucial and far from ideal. However, it was necessary since data were not available from literature. We attempted to validate the expert transitions; however, because of the scarce literature, this was only partly possible. Hence, a scenario analysis was performed to examine sensitivity of model results to these parameters. This analysis showed that model results are very sensitive to estimated transitions. Hence, empirical data to improve these estimates are strongly needed. As elaborated in the "Methods" section, we adhered to the formal requirements of the Delphi method and present our results with caution as the focus of this study was to build an up-to-date model for evaluation of OROS compared with IR rather than to gather comprehensive input to the model. One should note that participating experts received a small compensation, which was strictly limited to compensation for their invested time. The authors consider the collection of empirical data the necessary next step for further research.

In the current model, important societal costs and effects have been included (i.e., health care costs of caregiver, production losses of the caregiver and utilities of the caregiver). However, several aspects could not be covered, because of limited availability of data. Estimates of justice costs (i.e., incarceration costs, victim costs, etc.) could not be included, because of a lack of data in the considered age group and in the European context. Out-of-pocket expenses were not included as there was evidence from the Dutch literature that these costs were negligible [4]. However, when applying the current model to a different setting, country adaptation may be necessary, as a Belgian study [63] suggests differences in amounts of out-of-pocket expenses. These differences may be attributed to differences in sampling methods between the studies, but differences in health care systems may also play a role and necessitate model adaptation. Long-term effects on work and income have not been included in the model but are considered relevant. When taking a long-term perspective, these costs should be included in the model. Furthermore, in the current model, health care costs and production losses of the caregiver, which should be attributed to the behavioral problems of the child, were estimated at $25 \%$ of the total production losses. Mothers of children with ADHD had indicated that this percentage of their health care expenditures was related to the behavioral problems of their child. As it might be ethically difficult for a mother to blame her child for her medical problems, this estimate may be conservative. On the other hand, heritability of ADHD may point towards high medical expenditures of mothers for their own medical needs. Hence, in total, the chosen percentage might be a good estimate. Concerning the utilities of caregivers, the literature was especially limited. Hence, additional data are necessary to provide a better basis for future analyses. So, especially, concerning societal costs, available data were extremely scarce, and we emphasize the necessity for additional studies to close this gap.

Earlier cost-effectiveness results of the Faber model [29] resulted in incremental costs of $€ 276$ and incremental QALY gains of 0.13 of OROS compared with IR. The calculations in the current study resulted in mean incremental cost savings of $€ 5018$ and mean incremental QALY gains of 0.22 . The differences in costs can be explained by substantial revision of transition rates based on expert panel estimates, differences in model structure (e.g., consistent model states over treatment alternatives and omission of the state of 'remission' because of experts' opinion), update of cost parameters to 2014 values (including a slight price deflation on drug costs of OROS) and difference in time horizon. Compared with the transition rates presented by Faber et al. [29], which were based on a collection of different sources, the experts' transition rates based on the expert panel presented in this study showed significant differences. In the Faber model [29], no differentiation was made between the probability of patients in an optimal or in a suboptimal state to stop treatment (IR treatment arm). The same was true for the probability of patients in the optimal or suboptimal state to achieve functional remission or to transfer to a non-compliant/suboptimal state (OROS treatment arm). With respect to these probabilities, the Faber model [29] treated patients in an optimal and suboptimal state as being equal. These assumptions appear rather strong as they a priori prevented differences in compliance affecting the chance of functional remission or termination of treatment. In this study, on the contrary, the experts indicated clear differences between these transition probabilities (Table 5). Faber et al. [29] furthermore assumed a chance of moving from an optimal to a suboptimal state in the IR treatment arm to be 0 and the chance to stop treatment when non-compliant as 0 in the OROS arm. Both these assumptions appear counter-intuitive as they imply that a patient treated with IR may not miss a dose once he has achieved an optimal state and a non-compliant patient receiving OROS may not stop treatment at all. In the current study, the expert panel estimated all transition rates without assumptions beforehand to achieve a consistent framework of transition probabilities. As the transitions have a direct effect on how 
long patients remain in a state, these estimates have a strong influence on both incremental costs and effects and mainly explain the difference between the current model outcomes and those of the Faber model [29]. The transition estimates by the expert panel showed that patients receiving OROS were expected to be less likely to stop treatment, which corresponds to the findings from the literature on treatment duration and continuity [14, 15]. Furthermore, more patients receiving OROS were expected to move from a suboptimal state or a state were treatment was stopped back to an optimal state compared with patients receiving IR. These results are in line with the literature, as this suggests improved compliance of patients receiving OROS compared with those receiving IR [16-18]. However, the expert panel predicted the patients treated with OROS to have a lower probability to remain in an optimal state than patients receiving IR. This constitutes an unexpected finding given the literature on better compliance of patients receiving OROS [16-18]; hence, we consider collection of additional empirical data necessary.

The treatment effects in terms of quality of life were based on parental preferences. These were taken from an existing study by van der Kolk et al. [57]. It has been shown that the value of quality of life valuation by children themselves may be questionable, particularly because of lack of language, cognitive limitations, long-term perspective [82, 83] and conceptual difficulty of the standard gamble task [84]. Therefore, parental preferences were considered most appropriate for the young population of the current study. However, we are aware of the shortcomings of this approach, namely the inability of parents to accurately estimate invisible and subjective aspects of their child's quality of life, such as social and emotional functioning [82-85]. This limitation may lead to inaccurate estimates and a possible overestimation of the child's disability [86]. Besides the utility of the patient, we also included caregiver utility in the model. The proportion included was based on very limited evidence from the literature. As a scenario analysis showed, model results are sensitive to these utilities. Hence, additional data are needed. As economic cost-utility analysis and expressing outcomes in terms of QALYs is not yet common in the field of child and adolescent mental health [87], it may remain relevant for further studies to investigate results based both on costs/QALY and on costs per different (more clinically focused) outcome measures.

Severity of ADHD was not specified, but average severity was assumed in the model. One could, for instance, specify severity of ADHD in the model by distinguishing between the following categories of severity: (1) severe: no remission achievable; (2) moderate: $50 \%$ remission achievable; and (3) mild: $100 \%$ remission achievable. Furthermore, taking account of comorbidities may affect the costs entered in the model in such a way that part of the costs, e.g., special education, may not be attributed to ADHD alone but to behaviors which arise from a combination of comorbidities. In addition, long-term learning delay and emotional development problems were not taken into account in the current model. Hence, it should be noted that the current methodology is yet incomplete and that consideration of additions for long-term effects or consideration of different types of outcome measures to better account for the specific effects of mental health interventions may be necessary to improve the existing methodology.

Finally, as the focus of the study was the construction and demonstration of a broad and up-to-date probabilistic model compliant with current health economic methodology in this population rather than the provision of extensive input to the model, the model results should be interpreted with care. As can be seen from our results, future research should especially be directed at the collection of empirical data on transition estimates. We specifically suggest the collection of data from observational studies with large numbers of ADHD patients receiving (different types of) pharmaceutical treatment(s) compared with a control group of ADHD patients not treated with medication. It would be especially valuable to obtain data on treatment response (i.e., transition rates), health care use, school absence and performance, criminal activities and quality of life for these groups. To better cover the broad societal aspects, a very valuable and relevant addition would be data on the medical consumption, absence from work and utility of the caregivers and siblings as well. This information would be a valuable and necessary addition to the current model as it would lead to an increase in accuracy of the results and form a valuable basis for clinical and policy recommendations.

Acknowledgments The study was funded by Janssen-Cilag B.V., Tilburg (the Netherlands), a pharmaceutical company of Johnson \& Johnson. The authors would like to thank Adrianne Faber for her input connected to the existing health economic model constructed in 2008. Furthermore, the authors would like to thank the participating psychiatrists for their efforts and contribution to the expert panel.

Conflict of interest Saskia Schawo (SS), Clazien Bouwmans (CB), Leona Hakkaart-van Roijen (LH) and Lieven Annemans (LA) declare they have no conflicts of interest. Annemarie van der Kolk (AK) is an employee of Janssen-Cilag B.V. Michel van Agthoven (MA) is a former employee of Janssen-Cilag B.V. and current employee of Gilead Sciences Netherlands B.V. Maarten Postma (MP) has received grants, honoraria and travel support from various pharmaceutical companies, including the manufacturer of OROS. Jan Buitelaar (JB) has been, in the past 3 years, a consultant to/member of the advisory board of/and/or speaker for Janssen Cilag B.V., Eli Lilly, BristolMyer Squibb, Shering Plough, UCB, Shire, Novartis and Servier. He is not an employee of any of these companies and is not a stock shareholder of any of these companies. He has no other financial or material support, including expert testimony, patents, and royalties. 
Author contribution $\mathrm{CB}$ was involved in model design, the preparation of unit prices and the review of all versions of the manuscript. LH was involved in the overall design of the study, model design, expert consultation, review of all versions of the manuscript, program supervision and interpretation of model results. On behalf of the sponsor, AK and MA were involved in the design of the study, which was based on a previous health economic model co-developed by Janssen-Cilag B.V. Furthermore, they contributed to the model design, performed the Delphi panel and were involved in the preparation, review and approval of the manuscript. AK was also involved in the systematic literature review. MA was involved in the design and publication of the Faber model that was adapted in this study. JB contributed to the model design, acted as an expert advisor and reviewed the manuscript. MP and LA were involved as expert advisors. SS was involved in the model design, model programming, systematic literature review, expert consultation, interpretation of model results and writing the manuscript. All authors approved the final version of the manuscript.

Ethical standards For the preparation of the manuscript, no clinical study or patient data collection was performed.

Open Access This article is distributed under the terms of the Creative Commons Attribution Noncommercial License which permits any noncommercial use, distribution, and reproduction in any medium, provided the original author(s) and the source are credited.

\section{References}

1. Visser SN, Danielson ML, Bitsko RH, Holbrook JR, Kogan MD, Ghandour RM, et al. Trends in the parent-report of health care provider-diagnosed and medicated attention-deficit/hyperactivity disorder: United States, 2003-2011. J Am Acad Child Adolesc Psychiatry. 2014;53(1):34e2-46e2.

2. van den Ban E, Souverein P, Swaab H, van Engeland H, Heerdink $\mathrm{R}$, Egberts T. Trends in incidence and characteristics of children, adolescents, and adults initiating immediate- or extended-release methylphenidate or atomoxetine in the Netherlands during 2001-2006. J Child Adolesc Psychopharmacol. 2010;20(1):55-61.

3. Wicks-Nelson R, Israel AC. Abnormal Child and Adolescent Psychology. 8th ed. New York: Pearson; 2013.

4. Hakkaart-van Roijen L, Zwirs BW, Bouwmans C, Tan SS, Schulpen TW, Vlasveld L, et al. Societal costs and quality of life of children suffering from attention deficient hyperactivity disorder (ADHD). Eur Child Adolesc Psychiatry. 2007;16(5):316-26.

5. Lara C, Fayyad J, de Graaf R, Kessler RC, Aguilar-Gaxiola S, Angermeyer $\mathrm{M}$, et al. Childhood predictors of adult attentiondeficit/hyperactivity disorder: results from the World Health Organization World Mental Health Survey Initiative. Biol Psychiatry. 2009;65(1):46-54.

6. Tuithof $M$, Ten Have $M$, van Dorsselaer S, De Graaf $R$. Prevalentie, persistentie en gevolgen van ADHD in de Nederlandse volwassen bevolking. Tijdschrift voor Psychiatrie. 2014;56:10-9.

7. Doshi JA, Hodgkins P, Kahle J, Sikirica V, Cangelosi MJ, Setyawan J, et al. Economic impact of childhood and adult attention-deficit/hyperactivity disorder in the United States. J Am Acad Child Adolesc Psychiatry. 2012;51(10):990e2-1002e2.

8. Le HH, Hodgkins P, Postma MJ, Kahle J, Sikirica V, Setyawan J, et al. Economic impact of childhood/adolescent ADHD in a European setting: the Netherlands as a reference case. Eur Child Adolesc Psychiatry. 2013.
9. Landelijke Stuurgroep Multidisciplinaire Richtlijnontwikkeling in de GGZ. Multidisciplinaire richtlijn ADHD-Richtlijn voor de diagnostiek en behandeling van ADHD bij kinderen en jeugdigen. 2005.

10. Wolraich ML, Greenhill LL, Pelham W, Swanson J, Wilens T, Palumbo D, et al. Randomized, controlled trial of OROS methylphenidate once a day in children with attention-deficit/ hyperactivity disorder. Pediatrics. 2001;108(4):883-92.

11. Pelham WE, Gnagy EM, Burrows-Maclean L, Williams A, Fabiano GA, Morrisey SM, et al. Once-a-day Concerta methylphenidate versus three-times-daily methylphenidate in laboratory and natural settings. Pediatrics. 2001;107(6):E105.

12. Biederman J, Mick EO, Surman C, Doyle R, Hammerness P, Michel E, et al. Comparative acute efficacy and tolerability of OROS and immediate release formulations of methylphenidate in the treatment of adults with attention-deficit/hyperactivity disorder. BMC Psychiatry. 2007;7:49.

13. Claxton AJ, Cramer J, Pierce C. A systematic review of the associations between dose regimens and medication compliance. Clin Ther. 2001;23(8):1296-310.

14. Kemner JE, Lage MJ. Impact of methylphenidate formulation on treatment patterns and hospitalizations: a retrospective analysis. Ann Gen Psychiatry. 2006;5:5.

15. Marcus SC, Wan GJ, Kemner JE, Olfson M. Continuity of methylphenidate treatment for attention-deficit/hyperactivity disorder. Arch Pediatr Adolesc Med. 2005;159(6):572-8.

16. Adler LD, Nierenberg AA. Review of medication adherence in children and adults with ADHD. Postgrad Med. 2010;122(1): 184-91.

17. Christensen L, Sasane R, Hodgkins P, Harley C, Tetali S. Pharmacological treatment patterns among patients with attention-deficit/hyperactivity disorder: retrospective claims-based analysis of a managed care population. Curr Med Res Opin. 2010;26(4): 977-89.

18. Gau SS, Shen HY, Chou MC, Tang CS, Chiu YN, Gau CS. Determinants of adherence to methylphenidate and the impact of poor adherence on maternal and family measures. J Child Adolesc Psychopharmacol. 2006;16(3):286-97.

19. Brouwer W, van Exel J, Tilford M. Incorporating caregiver and family effects in economic evaluations of child health. In: Ungar W, editor. Economic Evaluation in Child Health. Oxford: Oxford University Press; 2010.

20. Beecham J. Annual research review: Child and adolescent mental health interventions: a review of progress in economic studies across different disorders. J Child Psychol Psychiatry. 2014;55(6):714-32.

21. Bernfort L, Nordfeldt S, Persson J. ADHD from a socio-economic perspective. Acta Paediatr. 2008;97(2):239-45.

22. Wu EQ, Hodgkins P, Ben-Hamadi R, Setyawan J, Xie J, Sikirica $\mathrm{V}$, et al. Cost effectiveness of pharmacotherapies for attentiondeficit hyperactivity disorder: a systematic literature review. CNS Drugs. 2012;26(7):581-600.

23. Al-Janabi H, Van Exel J, Brouwer W, Trotter C, Glennie L, Hannigan L, et al. The family impact of meningitis: a crosssectional analysis of long-term outcomes for survivors' family networks. To be submitted.

24. King. S, Griffin S, Hodges Z, Weatherly H, Asseburg C, Richardson G, et al. A systematic review and economic model of the effectiveness and cost-effectiveness of methylphenidate, dexamfetamine and atomoxetine for the treatment of attention deficit hyperactivity disorder in children and adolescents. Health Technol Assess. 2006;10(23).

25. Marchetti A, Magar R, Lau H, Murphy EL, Jensen PS, Conners CK, et al. Pharmacotherapies for attention-deficit/hyperactivity disorder: expected-cost analysis. Clin Ther. 2001;23(11):1904-21. 
26. Pelham WE, Foster EM, Robb JA. The economic impact of attention-deficit/hyperactivity disorder in children and adolescents. J Pediatr Psychol. 2007;32(6):711-27.

27. Cottrell S, Tilden D, Robinson P, Bae J, Arellano J, Edgell E, et al. A modeled economic evaluation comparing atomoxetine with stimulant therapy in the treatment of children with attentiondeficit/hyperactivity disorder in the United Kingdom. Value Health. 2008;11(3):376-88.

28. Hong J, Dilla T, Arellano J. A modelled economic evaluation comparing atomoxetine with methylphenidate in the treatment of children with attention-deficit/hyperactivity disorder in Spain. BMC Psychiatry. 2009;9:15.

29. Faber A, van Agthoven M, Kalverdijk LJ, Tobi H, de Jong-van den Berg LT, Annemans L, et al. Long-acting methylphenidateOROS in youths with attention-deficit hyperactivity disorder suboptimally controlled with immediate-release methylphenidate: a study of cost effectiveness in The Netherlands. CNS Drugs. 2008;22(2):157-70.

30. College voor Zorgverzekeringen. Dutch guidelines for pharmacoeconomic research. revised ed. Diemen: College voor Zorgverzekeringen; 2006.

31. Jonsson B. Ten arguments for a societal perspective in the economic evaluation of medical innovations. Eur $\mathrm{J}$ Health Econ. 2009; 10:357-9.

32. Secnik K, Matza LS, Cottrell S, Edgell E, Tilden D, Mannix S. Health state utilities for childhood attention-deficit/hyperactivity disorder based on parent preferences in the United Kingdom. Med Decis Making. 2005;25(1):56-70.

33. Briggs A, Claxton K, Sculpher M. Decision Modelling for Health Economic Evaluation. New York: Oxford University Press; 2006.

34. Jensen PS, Hinshaw SP, Swanson JM, Greenhill LL, Conners CK, Arnold LE, et al. Findings from the NIMH Multimodal Treatment Study of ADHD (MTA): implications and applications for primary care providers. J Dev Behav Pediatr. 2001;22(1):60-73.

35. Coghill D, Banaschewski T, Zuddas A, Pelaz A, Gagliano A, Doepfner M. Long-acting methylphenidate formulations in the treatment of attention-deficit/hyperactivity disorder: a systematic review of head-to-head studies. BMC Psychiatry. 2013;13:237.

36. Armstrong RB, Damaraju CV, Ascher S, Schwarzman L, O’Neill J, Starr HL. Time course of treatment effect of OROS(R) methylphenidate in children with ADHD. J Atten Disord. 2012;16(8):697-705.

37. Pelz R, Banaschewski T, Becker K. Methylphenidate of retard forms in children and adolescents with ADHD - an overview. Klin Padiatr. 2008;220(2):93-100.

38. Wigal SB. Efficacy and safety limitations of attention-deficit hyperactivity disorder pharmacotherapy in children and adults. CNS Drugs. 2009;23(Suppl 1):21-31.

39. Hodgkins P, Shaw M, Coghill D, Hechtman L. Amfetamine and methylphenidate medications for attention-deficit/hyperactivity disorder: complementary treatment options. Eur Child Adolesc Psychiatry. 2012;21(9):477-92.

40. Maldonado R. Comparison of the pharmacokinetics and clinical efficacy of new extended-release formulations of methylphenidate. Expert Opin Drug Metab Toxicol. 2013;9(8):1001-14.

41. Catala-Lopez F, Ridao M, Sanfelix-Gimeno G, Peiro S. Costeffectiveness of pharmacological treatment of attention deficit hyperactivity disorder in children and adolescents: qualitative synthesis of scientific evidence. Rev Psiquiatr Salud Ment. 2013;6(4):168-77.

42. Jerome L. Effects of methylphenidate on acute math performance in children with ADHD. Can J Psychiatry. 2014;59(5):290.

43. Qi R, Zhang LJ, Lu GM. Emphasize the effect of methylphenidate on brain function in attention-deficit/hyperactivity disorder research. JAMA Psychiatry. 2014;71(2):210.
44. Shahrbabaki ME, Sabzevari L, Haghdoost A, Ashtiani R. A randomized double blind crossover study on the effectiveness of buspirone and methylphenidate in treatment of attention deficit/ hyperactivity disorder in children and adolescents. Iran J Psychiatry Clin Psychol. 2013;18(4):292-7.

45. Barragan E, Breuer D, Dopfner M. Efficacy and safety of omega$3 / 6$ fatty acids, methylphenidate, and a combined treatment in children with ADHD. J Atten Disord. 2014. doi:10.1177/ 1087054713518239

46. Robb AS, Findling RL, Childress AC, Berry SA, Belden HW, Wigal SB. Efficacy, safety, and tolerability of a novel methylphenidate extended-release oral suspension (MEROS) in ADHD. J Atten Disord. 2014.

47. Ghanizadeh A, Sayyari Z, Mohammadi MR. Effect of methylphenidate and folic acid on ADHD symptoms and quality of life and aggression: a randomized double blind placebo controlled clinical trial. Iran J Psychiatry. 2013;8(3):108-12.

48. Sobanski E, Dopfner M, Ose C, Fischer R. A non-interventional study of extended-release methylphenidate in the routine treatment of adolescents with ADHD: effectiveness, safety and adherence to treatment. Atten Defic Hyperact Disord. 2013;5(4):387-95.

49. Garg J, Arun P, Chavan BS. Comparative short term efficacy and tolerability of methylphenidate and atomoxetine in attention deficit hyperactivity disorder. Indian Pediatr. 2014;51(7):550-4.

50. Soutullo C, Banaschewski T, Lecendreux M, Johnson M, Zuddas A, Anderson C, et al. A post hoc comparison of the effects of lisdexamfetamine dimesylate and osmotic-release oral system methylphenidate on symptoms of attention-deficit hyperactivity disorder in children and adolescents. CNS Drugs. 2013;27(9): $743-51$.

51. Evans C. The use of consensus methods and expert panels in pharmacoeconomic studies. Practical applications and methodological shortcomings. Pharmacoeconomics. 1997;12(2 Pt 1): 121-9.

52. Evans C, Crawford B. Expert judgement in pharmacoeconomic studies. Guidance and future use. Pharmacoeconomics. 2000;17(6):545-53.

53. Danckaerts M, Sonuga-Barke EJ, Banaschewski T, Buitelaar J, Dopfner M, Hollis C, et al. The quality of life of children with attention deficit/hyperactivity disorder: a systematic review. Eur Child Adolesc Psychiatry. 2010;19(2):83-105.

54. Graetz BW, Sawyer MG, Hazell PL, Arney F, Baghurst P. Validity of DSM-IVADHD subtypes in a nationally representative sample of Australian children and adolescents. J Am Acad Child Adolesc Psychiatry. 2001;40(12):1410-7.

55. Matza LS, Secnik K, Mannix S, Sallee FR. Parent-proxy EQ-5D ratings of children with attention-deficit hyperactivity disorder in the US and the UK. Pharmacoeconomics. 2005;23(8):777-90.

56. Sawyer MG, Whaites L, Rey JM, Hazell PL, Graetz BW, Baghurst P. Health-related quality of life of children and adolescents with mental disorders. J Am Acad Child Adolesc Psychiatry. 2002;41(5):530-7.

57. van der Kolk A, Bouwmans CA, Schawo SJ, Buitelaar JK, van Agthoven M, Hakkaart-van Roijen L. Association between quality of life and treatment response in children with attention deficit hyperactivity disorder and their parents. J Ment Health Policy Econ. 2014;17(3):119-29.

58. Brooks R, Rabin R, De Charro F. The measurement and valuation of health status using EQ-5D: a European perspective: evidence from the EuroQol BIOMED Research Programme. New York: Springer; 2003.

59. Baldwin S, Gerard K. Caring at home for the children with mental handicaps. In: Baldwin S, Godfrey C, Propper C, editors. Quality of life: perspectives and policy. London: Routledge; 1990. 
60. Parker G. Spouse Carers. Whose quality of life? In: Baldwin S, Godfrey C, Propper C, editors. The quality of life: perspectives and policies. London: Routledge; 1990.

61. Basu A, Meltzer D. Implications of spillover effects within the family for medical cost-effectiveness analysis. J Health Econ. 2005;24(4):751-73.

62. De Meijer C, Brouwer W, Koopmanschap M, Van den Berg B, Van Exel J. The value of informal care-a further investigation of the feasibility of contingent valuation in informal caregivers. Health Econ. 2010;19(7):755-71.

63. De Ridder A, De Graeve D. Healthcare use, social burden and costs of children with and without ADHD in Flanders, Belgium. Clin Drug Investig. 2006;26(2):75-90.

64. Hakkaart L, Tan S, Bouwmans C. Manual for costing research (in Dutch). Amstelveen: Healthcare Insurance Board; 2010.

65. Ministry of Education, Culture and Science. Kerncijfers 2007-2011 onderwijs, cultuur, wetenschap. 2012.

66. IMS Health BV. Patient Level Study Concerta. 2008.

67. Zorginstituut Nederland. Medicijnkosten. 2014. http://www. medicijnkosten.nl. Accessed 12/18, 2014.

68. Barkley RA, Fischer M, Smallish L, Fletcher K. Young adult follow-up of hyperactive children: antisocial activities and drug use. J Child Psychol Psychiatry. 2004;45(2):195-211.

69. Sourander A, Elonheimo H, Niemela S, Nuutila AM, Helenius H, Sillanmaki L, et al. Childhood predictors of male criminality: a prospective population-based follow-up study from age 8 to late adolescence. J Am Acad Child Adolesc Psychiatry. 2006;45(5): 578-86.

70. Mannuzza S, Klein RG, Bessler A, Malloy P, LaPadula M. Adult psychiatric status of hyperactive boys grown up. Am J Psychiatry. 1998;155(4):493-8.

71. Vitelli R. Prevalence of childhood conduct and attention-deficit hyperactivity disorders in adult maximum-security inmates. Int $\mathrm{J}$ Offender Ther Comp Criminol. 1996;40(4):263-71.

72. Lichtenstein P, Halldner L, Zetterqvist J, Sjolander A, Serlachius E, Fazel S, et al. Medication for attention deficit-hyperactivity disorder and criminality. N Engl J Med. 2012;367(21):2006-14.

73. Loe IM, Feldman HM. Academic and educational outcomes of children with ADHD. J Pediatr Psychol. 2007;32(6):643-54.

74. Mannuzza S, Klein RG, Bessler A, Malloy P, LaPadula M. Adult outcome of hyperactive boys. Educational achievement, occupational rank, and psychiatric status. Arch Gen Psychiatry. 1993;50(7):565-76.

75. Teeter P. Interventions for ADHD: treatment in developmental context. New York: Guilford Press; 1998.

76. Biederman J, Petty CR, Fried R, Kaiser R, Dolan CR, Schoenfeld $\mathrm{S}$, et al. Educational and occupational underattainment in adults with attention-deficit/hyperactivity disorder: a controlled study. J Clin Psychiatry. 2008;69(8):1217-22.

77. Biederman J, Faraone SV. The effects of attention-deficit/hyperactivity disorder on employment and household income. Med Gen Med. 2006;8(3):12.

78. Klein RG, Mannuzza S, Olazagasti MA, Roizen E, Hutchison JA, Lashua EC, et al. Clinical and functional outcome of childhood attention-deficit/hyperactivity disorder 33 years later. Arch Gen Psychiatry. 2012;69(12):1295-303.

79. Swanson J. Compliance with stimulants for attention-deficit/hyperactivity disorder: issues and approaches for improvement. CNS Drugs. 2003;17(2):117-31.

80. Fenwick E, Byford S. A guide to cost-effectiveness acceptability curves. Br J Psychiatry. 2005;187:106-8.

81. Fenwick E, O’Brien BJ, Briggs A. Cost-effectiveness acceptability curves-facts, fallacies and frequently asked questions. Health Econ. 2004;13(5):405-15.

82. Petrou S. Methodological issues raised by preference-based approaches to measuring the health status of children. Health Econ. 2003;12(8):697-702.

83. Vogels T, Verrips GH, Verloove-Vanhorick SP, Fekkes M, Kamphuis RP, Koopman HM, et al. Measuring health-related quality of life in children: the development of the TACQOL parent form. Q Life Res. 1998;7(5):457-65.

84. Juniper EF, Guyatt GH, Feeny DH, Griffith LE, Ferrie PJ. Minimum skills required by children to complete health-related quality of life instruments for asthma: comparison of measurement properties. Eur Respir J. 1997;10(10):2285-94.

85. Sprangers MA, Aaronson NK. The role of health care providers and significant others in evaluating the quality of life of patients with chronic disease: a review. J Clin Epidemiol. 1992;45(7): 743-60.

86. Glaser AW, Davies K, Walker D, Brazier D. Influence of proxy respondents and mode of administration on health status assessment following central nervous system tumours in childhood. Qual Life Res. 1997;6(1):43-53.

87. Romeo R, Byford S, Knapp M. Annotation: Economic evaluations of child and adolescent mental health interventions: a systematic review. J Child Psychol Psychiatry. 2005;46(9): 919-30.

88. College tarieven gezondheidszorg. Tariffs AWBZ-institutions 2005. 2013. http://www.ctg.zaio.nl., 2013.

89. Dutch Society of Remedial Teachers. Standard prices. 2013. http://www.lbrt.nl., 2013.

90. Health Care Insurance Board. Personal budget. 2013. http://www. cvz.nl/cijfers_en_publicaties/brochures_en_folders/zorginkopen_ pgb.asp., 2013. 